\title{
Interaction between large herbivore activities, vegetation structure, and flooding affects tree seedling emergence
}

\author{
Jan Van Uytvanck · Tanja Milotic • \\ Maurice Hoffmann
}

Received: 27 February 2009/Accepted: 18 June 2009/Published online: 2 July 2009

(C) Springer Science+Business Media B.V. 2009

\begin{abstract}
Tree establishment in grazed vegetation mosaics involves a series of early bottlenecks, including seed dispersal, germination, seedling emergence, survival and growth. In a field experiment, we studied seedling emergence of two species with contrasting recruitment strategies, Fraxinus excelsior and Quercus robur, in five structurally different vegetations: grazed and ungrazed grassland, ruderal pioneer vegetation, soft rush tussocks, tall sedge mats and bramble scrub. In a simulation experiment, we studied the interaction effects of pre-emergence flooding (3 weeks of inundation), trampling and grazing (simulated by clipping) of grassland vegetation on the emergence and early growth of both tree species in grass swards. Seedling emergence was enhanced in low swards and sparse vegetation types. Despite different recruitment strategies, the interaction of flooding and trampling of swards enhanced seedling emergence of both species. Grazing of soft rush and tall sedges enhanced emergence of $F$. excelsior.
\end{abstract}

J. Van Uytvanck ( $₫)$. T. Milotic · M. Hoffmann Research Institute for Nature and Forest, Kliniekstraat 25, 1070 Brussels, Belgium

e-mail: jan.vanuytvanck@inbo.be

M. Hoffmann

e-mail: maurice.hoffmann@inbo.be

J. Van Uytvanck · M. Hoffmann

Terrestrial Ecology Unit, Department of Biology, Ghent University, K.L. Ledeganckstraat 35, 9000 Ghent,

Belgium
Clipping grass swards increased early growth of emerging $Q$. robur. Our results support the hypothesis that natural disturbances of soil and vegetation create microsites for seedling emergence and reduce aboveground competition. In grazed systems however, these results suggest a discordant relationship between successful seedling emergence and subsequent seedling growth/survival during the establishment process in structurally different vegetations.

Keywords Competition for light · Grazing · Natural disturbances - Tree recruitment and establishment · Trampling · Vegetation gap

\section{Introduction}

Grazed wetlands are often characterized by mosaic landscapes with grassland, scattered scrub, trees and forest patches (van der Valk and Warner 2009). Regular or periodic tree establishment is necessary for the continued existence of this structural heterogeneity (Olff et al. 1999). Herbivore activity and its interaction with surrounding spatial structure (e.g. Van Uytvanck et al. 2008b) and flooding are important ecological determinants for successful tree establishment.

Recruitment of woody species in grassland ecosystems is often episodic and disturbance-driven (Putman 1986; Grubb 1988; Clarke 2002). Generally, a dense grass canopy drastically reduces favourable 
microsites for germination and emergence and subsequent growth (above and below ground) and survival rate of seedlings (Eriksson and Ehrlén 1992; Davis et al. 1999; Mazia et al. 2001; Harmer and Robertson 2003; Setterfield 2002). Flooding in wetland ecosystems may cause die back or retard growth of grassland vegetation, temporarily reduce grass and herb competition and favour flood tolerant tree seedlings such as Ulmus species, Quercus robur and Fraxinus excelsior (Deiller et al. 2003; Kühne and Bartsch 2007). Additionally, local erosion and sedimentation following flooding (Van Splunder et al. 1995), but also soil trampling by large herbivores (Trimble and Mendel 1995), may create bare ground patches and small gaps in the grass layer. These may function as microsites for germination and emergence of woody species (Posada et al. 2000). In the absence or reduced presence of litter or roots (when destroyed or damaged by trampling) in the upper soil layers, radicles of germinated tree seeds may penetrate the soil easier avoiding early desiccation, which is a common failure for tree seedling establishment (Caccia and Ballaré 1998). Large herbivores locally create short grassland lawns by grazing. In these lawns, a reduced vegetation height allows partial release from competition for light, water, nutrients and space (Nilsson et al. 2002). As a consequence, lawns may provide additional opportunities for the establishment of woody plants (Jurena and Archer 2003; Vandenberghe et al. 2006; Hagenah et al. 2009). In contrast to tall and dense vegetation, short grazed lawns and gaps may also experience reduced seed predation by small herbivores such as rodents (Kelt et al. 2004). On the other hand, early and fragile seedlings in lawns may suffer from direct solar radiation and be less protected from heat and drought compared to seedlings emerging under the protection of surrounding vegetation (Berkowitz et al. 1995; Vandenberghe et al. 2006).

In the subsequent life stage, survival and growth of seedlings may be highly restricted by large herbivore grazing, even at low stocking rates (Van Uytvanck et al. 2008b). Therefore, increased opportunities for germination and emergence of woody species in microsites created by uprooting, trampling or grazing may be followed by increased mortality of saplings by desiccation or grazing of favoured grassland lawns. In this article, we study the individual effects and interactions of large herbivore activities (grazing, trampling), vegetation structure and flooding on tree seedling emergence and early seedling growth of $F$. excelsior and $Q$. robur. Both species are found in European lowland woodlands on a wide range of soil types with varying soil texture, $\mathrm{pH}$, trophic and hydrological conditions. Both are important pioneer species, invading grasslands where there are openings in the sward (Jones 1959; Wardle 1961; Rudinger and Dounavi 2008), and they are suitable model species for a broad range of palatable tree species that regenerate naturally in grazed grassland ecosystems. Recruitment strategies of $Q$. robur and $F$. excelsior significantly differ in (1) seed characteristics: seed mass (heavy versus light), longevity (transient versus short-term persistent), dormancy (short versus long); (2) dispersal vector (diplochory with animals as secondary dispersers versus primarily wind and water), dropping off trees (fast versus slow) and (3) seedling light requirements (strongly light demanding for survival versus shade-tolerant persistent seedlings).

We set up a field experiment to investigate the role of the vegetation structure and grazing on seedling emergence of $F$. excelsior and $Q$. robur. We elaborated on a previous study in which the seedling stage (survival and growth of planted individuals) of both species was investigated in five structurally different vegetation types: grassland lawn, ruderal pioneer vegetation on former agricultural land, tall Juncus vegetation, tall Carex vegetation and Rubus (bramble) thickets (Van Uytvanck et al. 2008b). We hypothesized that $F$. excelsior and $Q$. robur seedling emergence will respond differently to vegetation structure type and grazing effects. We hypothesized that the emergence of $F$. excelsior will be favoured in low or sparse (and therefore less competitive) vegetation types such as grassland lawns and ruderal pioneer vegetations. We hypothesized that grazing will enhance emergence of this species in tall vegetation types (Juncus and Carex vegetation) by creating gaps and reducing competition. Both hypotheses are based on the adaptive traits of F. excelsior seeds: they can reach favourable sites (short or sparse vegetation types) through wind dispersal and they are able to wait favourable conditions through dormancy (shortened vegetation or gaps after grazing). In contrast, we hypothesized that the emergence of Q. robur is independent on vegetation structure and grazing, because it has large seeds without innate features to escape unfavourable conditions. Large seeds have a large amount of nutritional reserves, which favours seedling emergence and survival (Winn 
1985; Greiling and Kichanan 2002). Therefore, we hypothesized that competition of surrounding vegetation (whether influenced by grazing or not) does not influence emergence of $Q$. robur significantly. Second, we set up a greenhouse/garden simulation experiment to study the interaction of herbivore activities (grazing and trampling of grassland swards) and pre-emergence winter-early spring flooding on the emergence and early growth of seedlings of the same species. We hypothesized that disturbances (grazing, trampling and flooding) would decrease the ability of closed grassland swards to suppress emergence and early growth of seedlings. We hypothesized that grazing, pre-emergence trampling and flooding of grassland swards increase seedling emergence of $F$. excelsior. We hypothesized that these disturbances would not affect the emergence of $Q$. robur. We hypothesized that preemergence flooding enhances early growth of both species due to released competition.

\section{Methods}

Study sites and focal species

We conducted a field experiment on the emergence of $F$. excelsior and $Q$. robur in three nature reserves on former agricultural land in the southern part of Flanders (N-Belgium): Boelaremeersen, Rietbeemd and Steenbergbos. All sites were grazed with cattle (0.4-0.5 AU/ha/year; at Rietbeemd two ponies were added to the herd). For a detailed description of past and current land use and grazing management of those sites see Van Uytvanck et al. (2008b). We studied emergence in five structurally different vegetation types. We conducted a second, controlled experiment on the emergence of the same species under simulated natural disturbances in grassland, in a greenhouse and surrounding garden facilities in Wenduine $\left(51^{\circ} 17^{\prime} \mathrm{N} ; 3^{\circ} 03^{\prime} \mathrm{E}\right)$ in the western part of Flanders.

$Q$. robur and $F$. excelsior are two widespread, native, deciduous tree species with a similar distribution pattern in the European lowland (Jones 1959; Wardle 1961; Oberdorfer 1992). Both species occur in a broad range of woodlands and park landscapes (from hardwood floodplain forests to dry and welldrained forest on rendzina soils). Vera (2000) states that in grazed landscapes, juveniles and young trees occur preferentially in protective vegetation patches such as thorny or spiny thickets. Both species are able to produce a large number of seeds but seed production of $Q$. robur shows great variability between years, whereas yearly seed production of $F$. excelsior is more constant. However, Q. robur and F. excelsior differ considerably in recruitment strategy: $Q$. robur has a transient seed bank; seeds exhibit very little dormancy, but germination velocity is irregular and germination is spread over 1 year (Reyes and Casal 2006). Seeds are large and heavy, soon falling off and secondarily mainly dispersed by animals. Seedlings need sufficient light to survive, i.e. outside a closed tree canopy (Rackham 1980). In contrast, F. excelsior has winged, light seeds that are fixed for several months to tree branches and are mainly dispersed by wind, and to a lesser extent by water and birds. F. excelsior has a short-term persistent seed bank, restricted to 5-6 years, but with deeply dormant seeds that, in general, do not germinate until the second spring after dispersal (Thompson and Bekker 1997; Raquin et al. 2002; Willoughby et al. 2004). F. excelsior has shadetolerant persistent juveniles which are able to grow out quickly when light penetration increases (Tapper 1996).

\section{Experimental design}

For both experiments and model species, we acquired fruits (F. excelsior) and acorns ( $Q$. robur), each from one particular tree nearby the study sites $\left(50^{\circ} 46^{\prime} \mathrm{N}\right.$; $\left.3^{\circ} 45^{\prime} \mathrm{E}\right)$ at the end of October 2005 and 2006. We stored seeds at $4^{\circ} \mathrm{C}$ until planting. We only used healthy fruits (visual inspection) of $F$. excelsior that obviously contained seed ( $>5 \mathrm{~mm}$ in length, considered to be viable, Gardner 1977), and healthy acorns (unaffected by insect larvae, worms or fungi). We did not remove seeds from the $F$. excelsior fruits, because the long dormancy period does not result in a significant difference in germination percentage (Gardner 1977) and because fruits are the dispersal mode. In the field experiment, we studied the effect of grazing and vegetation structure on emergence. In the second week of November 2005, we planted 1,584 seeds and fruits of $Q$. robur and $F$. excelsior, each, in five structurally different vegetation types (Table 1): short grassland (short, dense lawns), soft rush vegetation (Juncus; high tussocks), tall sedge 
vegetation (Carex; tall mats), ruderal pioneer vegetation (short, sparse vegetation on former arable land) and bramble (Rubus; tall thickets). Identification and location of the vegetation types in the field was mainly based on cover percentage of dominant species and former land use (in case of arable land) (Van Uytvanck et al. 2008b). We planted seeds in 44 plots, consisting of a grazed and an ungrazed (barb wire exclosure against large herbivores) subplot $(2 \mathrm{~m} \times 2 \mathrm{~m})$. In ungrazed subplots, vegetation was taller, light penetration was decreased (Table 1). We divided each subplot in two parts $(1 \mathrm{~m} \times 2 \mathrm{~m})$, randomly assigned to the species, and planted 18 seeds and fruits of $Q$. robur and $F$. excelsior, respectively, just beneath ground level in a fixed $3 \times 6$ grid. This resulted in 176 experimental units.

In the controlled simulation experiment, we studied the effects of grazing, trampling and winter-early spring flooding on the emergence and early growth of tree seedlings. In November 2006, we planted 2,592 seeds and fruits of $Q$. robur and F. excelsior, each, in seed-bed plots in a cold greenhouse (average temperature November-January: $6.4 \pm 1.8^{\circ} \mathrm{C}$ ) with a natural light regime. Seed-bed plots consisted of previously sown grass swards (commercial grass mix, dominated by Lolium perenne) on a mixture of sterilized (heated at $180^{\circ} \mathrm{C}$ in an oven to obtain homogeneous grassland swards in all plots) and nutrient rich potting compost and sand. In each plot $(40 \mathrm{~cm} \times 42 \mathrm{~cm}), 36$ acorns or fruits were sown in a fixed $6 \times 6$ grid to account for seedlings that died and disappeared during the experiment. Plots were humidified to reduce desiccation of the seeds. In the first week of February 2006, we moved seed-bed plots with fully grown grass swards (cover $=100 \%$ ) outside the greenhouse to apply the treatments.

Plots were arranged in a three-way factorial, randomized complete block design. Treatments are combinations of three factors: species, trampling and clipping the seed-bed vegetation. One block consisted of eight plots. Within a block, one of eight possible factor combinations (i.e. clipping grass swards or not $\times$ trampling or not $\times$ two species) was randomly assigned to a plot. We established nine blocks, representing nine replicas. Superimposed on this, a fourth factor (flooding or not) was applied, using a similar set of nine blocks. This resulted in a total of 144 experimental units.

We flooded one set of nine blocks with rain water for ca. 3 weeks (27 February 2007-22 March 2007), simulating winter-early spring flooding (water surface $15-20 \mathrm{~cm}$ above ground level of plots). The other set of nine blocks was not flooded. Because emergence of $F$. excelsior seedlings only starts after a second winter, we repeated the flooding regime in 2008 for the F. excelsior plots only. Clipping of the swards (simulating grazed conditions) and trampling started before emergence and immediately after flooding was finished. Trampling the swards was only applied once (in 2007) for Q. robur, twice (2007 and 2008) for $F$. excelsior. Repeated clipping (every week) kept the sward height between 3 and $5 \mathrm{~cm}$. Unclipped vegetation resulted in a dense and high sward (average canopy height May-September $=25.1-38.4 \mathrm{~cm}$, Table 2) with bent grass stems and leaves and (in 2008) also litter production. We simulated trampling of the grass sward by large herbivores with a wooden cattle paw dummy (basal

Table 1 Field experiment: number of plots in different study sites and mean height, light penetration and soil moisture of different vegetation types

\begin{tabular}{|c|c|c|c|c|c|c|c|c|}
\hline & \multicolumn{3}{|c|}{ No. of plots } & \multicolumn{2}{|c|}{ Vegetation height $(\mathrm{cm})$} & \multicolumn{2}{|c|}{ Light penetration (\%) } & \multirow{2}{*}{$\begin{array}{l}\text { Soil moisture } \\
\text { (Ellenberg } \\
\text { value) }\end{array}$} \\
\hline & $\mathrm{BM}$ & $\mathrm{RB}$ & SB & Ungrazed & Grazed & Ungrazed & Grazed & \\
\hline Grassland & 5 & 4 & 4 & $54.6( \pm 19.0)$ & $21.9( \pm 9.94)$ & $84.0( \pm 18.0)$ & $89.9( \pm 14.5)$ & $6.3( \pm 0.2)$ \\
\hline Ruderal pioneer vegetation & - & - & 4 & $66.2( \pm 1.4)$ & $15.8( \pm 4.6)$ & $73.3( \pm 29.6)$ & $83.7( \pm .5)$ & $5.1( \pm 0.3)$ \\
\hline Soft rush tussocks (Juncus) & 5 & 4 & - & $92.2( \pm 11.6)$ & $74.1( \pm 13.1)$ & $58.1( \pm 21.2)$ & $72.6( \pm 18.0)$ & $7.0( \pm 0.1)$ \\
\hline Tall sedges (Carex) & 5 & - & - & $97.2( \pm 16.9)$ & $71.3( \pm 18.4)$ & $25.8( \pm 16.0)$ & $53.8( \pm 17.0)$ & $8.8( \pm 0.1)$ \\
\hline Bramble (Rubus) & 5 & 4 & 4 & $87.4( \pm 26.6)$ & $79.6( \pm 16.6)$ & $21.5( \pm 23.9)$ & $22.1( \pm 22.5)$ & $6.4( \pm 0.3)$ \\
\hline
\end{tabular}

Soil moisture is estimated, using weighted Ellenberg values for moisture of the species in the vegetation; weighting factor is cover of the individual species

$B M$ boelaremeersen, $R B$ rietbeemd, $S B$ steenbergbos 
hoof surface $=49 \mathrm{~cm}^{2}$ ): we made 25 imprints in each trampled plot by pressing the dummy on the vegetation and soil with a weight of $\pm 100 \mathrm{~kg}$ (i.e. $\pm 2 \mathrm{~kg} / \mathrm{cm}^{2}$, a comparable pressure of an adult cow's paw). This resulted in complete trampling of the vegetation (canopy height reduced to $0-5 \mathrm{~cm}$ above ground level) and disturbance in the upper $5( \pm 2) \mathrm{cm}$ of the soil in each trampling-subplot, creating hoof print gaps. We protected all plots from predation by birds using a fine-meshed net. Plots were kept humid by rain; in dry periods by sprinkling.

\section{Data collection}

In both experiments, we recorded a seedling as emerged if it had developed cotyledons, an epicotyl shoot and at least one leaf. In the field experiment, we recorded emergence of seedlings four times per year: in April, June, August and September 2006 and in 2007. We measured soil moisture, light penetration and vegetation height (see Van Uytvanck et al. 2008b) in all plots in September 2006. Vegetation height was always lower in grazed plots than in ungrazed plots and light penetration was always higher in grazed plots (Table 1).

In the simulation experiment, we recorded the emergence of seedlings twice during the growing season of 2007 (May and September) and repeated this for $F$. excelsior in 2008. We measured shoot height of all emerged seedlings in the last recording session in September. We measured vegetation height at the same time of emergence recording on four fixed points. At the same time, we measured photosynthetic photon flux density $\left(\mu \mathrm{mol}\right.$ photons $\left./ \mathrm{s} / \mathrm{m}^{2}\right)$ in all plots. We made these measurements at ground level (same four fixed points) and $50 \mathrm{~cm}$ (point without interfering vegetation) above ground level with a photometer (SKP 200, Skye Instruments Ltd., Powys, UK). We determined light penetration in the vegetation as the ratio between paired measurements at 0 and $50 \mathrm{~cm}$ (Table 2).

A problem arose when, in May 2007, a substantial part of the acorns was dug out and predated or removed by the small rodent Eliomys quercinus that had entered the experimental setup of the garden experiment. $45.7 \%$ of the acorns were removed or predated. Three flooded acorn blocks were highly affected (predation $>70 \%$ ). Therefore, we recorded the number of removed or predated acorns per plot to correct the percentages of emerged seedlings. F. excelsior seeds were not affected by predation.

\section{Data analyses}

We conducted statistical analyses using SAS 9.1. We used generalized linear-mixed models (proc glimmix in SAS 9.1) to analyse the number of emerged seedlings in both experiments. Because of differences in germination velocity within one species, we used the total of emerged individuals as recorded after the final observations in both experiments, i.e. after 10 and 22 months for $Q$. robur and F. excelsior, respectively. Because we could not correct for differences in seed viability and germination rate between species, $Q$. robur and F. excelsior were analysed separately in both experiments. The response variable was log-transformed to

Table 2 Simulation experiment: grass sward characteristics after different treatments (1 values \pm SD)

\begin{tabular}{|c|c|c|c|c|c|c|c|c|}
\hline & \multicolumn{4}{|c|}{ Pre-emergence flooding } & \multicolumn{4}{|l|}{ No flooding } \\
\hline & \multicolumn{2}{|l|}{ Clipped } & \multicolumn{2}{|l|}{ Unclipped } & \multicolumn{2}{|l|}{ Clipped } & \multicolumn{2}{|l|}{ Unclipped } \\
\hline & Untrampled & Trampled & Untrampled & Trampled & Untrampled & Trampled & Untrampled & Trampled \\
\hline \multicolumn{9}{|l|}{ Height $(\mathrm{cm})$} \\
\hline May & Kept between & 3 and $5 \mathrm{~cm}$ & $25.6 \pm 25.0$ & $22.8 \pm 20.3$ & Kept between & 3 and $5 \mathrm{~cm}$ & $26.3 \pm 12.5$ & $26.0 \pm 11.3$ \\
\hline September & & & $40.1 \pm 12.1$ & $37.3 \pm 18.3$ & & & $39.3 \pm 18.2$ & $37.0 \pm 15.8$ \\
\hline \multicolumn{9}{|l|}{ Cover (\%) } \\
\hline May & $97.5 \pm 5.1$ & $71.3 \pm 12.1$ & $96.1 \pm 4.8$ & $66.1 \pm 14.7$ & 100 & $96.3 \pm 3.9$ & 100 & $95.9 \pm 2.6$ \\
\hline September & 100 & 100 & 100 & 100 & 100 & 100 & 100 & 100 \\
\hline \multicolumn{9}{|c|}{ Light penetration (\%) } \\
\hline May & $98.9 \pm 3.1$ & $99.2 \pm 2.2$ & $63.4 \pm 7.1$ & $87.1 \pm 9.4$ & $99.0 \pm 2.0$ & $97.6 \pm 4.9$ & $62.6 \pm 6.6$ & $52.2 \pm 8.1$ \\
\hline September & $99.6 \pm 1.4$ & $99.1 \pm 2.7$ & $71.3 \pm 8.3$ & $68.4 \pm 9.1$ & $97.8 \pm 1.9$ & $99.3 \pm 0.9$ & $68.7 \pm 8.4$ & $69.9 \pm 9.8$ \\
\hline
\end{tabular}


meet conditions for normality. Shoot height (simulation experiment) was analysed using general linear models (proc glm in SAS 9.1). AIC values for goodness-of-model-fit were used to control whether the model was improved or not after backward elimination of non-significant factors. Tukey tests were performed to make multiple comparisons in all analyses.

For the field experiment, we entered study site and plot (nested in vegetation type) as random factors in the model. Vegetation type and grazing (yes or no) and their interaction were entered as fixed factors. For the simulation experiment, we entered flooding, trampling, clipping and all interactions as fixed factors.

\section{Results}

Field experiment: the role of vegetation structure and grazing on emergence

For both tree species, short and sparse vegetation types (grassland lawns and ruderal pioneer vegetations) showed significantly higher emergence percentages compared to soft rush, tall sedges and bramble thickets. For $F$. excelsior, grazing interacted with vegetation structure: comparable emergence percentages were found in short and sparse vegetation types and in grazed soft rush and tall sedges (Table 3; Fig. 1). For $Q$. robur, grazing did not affect seedling emergence significantly. Average emergence rate for $Q$. robur was $11.71 \%$ ( \pm 10.05$)$; for $F$. excelsior it was $10.63 \%$ $( \pm 5.22)$. Random factors site $(Q$. robur: estimate $=$ $0.024 \pm 0.029 \mathrm{SE} ;$ F. excelsior: estimate $=0.110 \pm$ $0.114 \mathrm{SE})$ and plot $(Q$. robur: estimate $=0.012 \pm$ 0.011 SE; F. excelsior: $0.014 \pm 0.012 \mathrm{SE}$ ) had a negligible effect on emergence, as compared to fixed effect factors, but were kept in the model as they are inherent to the study's experimental design. $Q$. robur emergence was restricted to the first year after acorn planting.

Simulation experiment: the role of natural disturbances on emergence and shoot growth

Cover and height of grass swards (initially $=100 \%$ ) were reduced after trampling and flooding. In dry
Table 3 Seedling emergence \%-results of the GLM analyses

\begin{tabular}{|c|c|c|c|c|c|}
\hline & Independent factor & Nom. df & Den. df & $F$ value & $\operatorname{Pr}>F$ \\
\hline \multicolumn{6}{|c|}{ Field experiment } \\
\hline \multirow[t]{3}{*}{ F. excelsior } & Veg & 4 & 78 & 97.67 & $<0.001$ \\
\hline & Grazing & 1 & 78 & 3.75 & 0.084 \\
\hline & Veg*grazing & 4 & 78 & 14.00 & $<0.001$ \\
\hline \multirow[t]{3}{*}{ Q. robur } & Veg & 4 & 78 & 97.67 & $<0.001$ \\
\hline & Grazing & 1 & 78 & 3.75 & 0.056 \\
\hline & Veg*grazing & 4 & 78 & 0.88 & 0.654 \\
\hline \multicolumn{6}{|c|}{ Simulation experiment } \\
\hline \multirow[t]{7}{*}{ F. excelsior } & Clipping seed-bed vegetation & 1 & 64 & 9.14 & 0.004 \\
\hline & Flooding & 1 & 64 & 59.86 & $<0.001$ \\
\hline & Trampling & 1 & 64 & 1.87 & 0.176 \\
\hline & Clipping*trampling & 1 & 64 & 2.25 & 0.138 \\
\hline & Clipping*flooding & 1 & 64 & 3.27 & 0.075 \\
\hline & Trampling*flooding & 1 & 64 & 9.17 & 0.004 \\
\hline & Clipping*trampling*flooding & 1 & 64 & 4.54 & 0.037 \\
\hline \multirow[t]{7}{*}{ Q. robur } & Clipping seed-bed vegetation & 1 & 64 & 32.08 & $<0.001$ \\
\hline & Flooding & 1 & 64 & 7.83 & 0.007 \\
\hline & Trampling & 1 & 64 & 5.34 & 0.024 \\
\hline & Clipping*trampling & 1 & 64 & 2.66 & 0.108 \\
\hline & Clipping*flooding & 1 & 64 & 3.05 & 0.086 \\
\hline & Trampling*flooding & 1 & 64 & 11.11 & 0.002 \\
\hline & Clipping*trampling*flooding & 1 & 64 & 3.10 & 0.083 \\
\hline
\end{tabular}


Fig. 1 Emergence \% $(+\mathrm{SE})$ of tree seedlings (F. excelsior and $Q$. robur) in five different vegetation types in grazed and ungrazed conditions (field experiment). Different letters indicate significantly different values (multiple comparisons with Tukeytests, $P<0.05)$ per species. Differences between species are not analysed
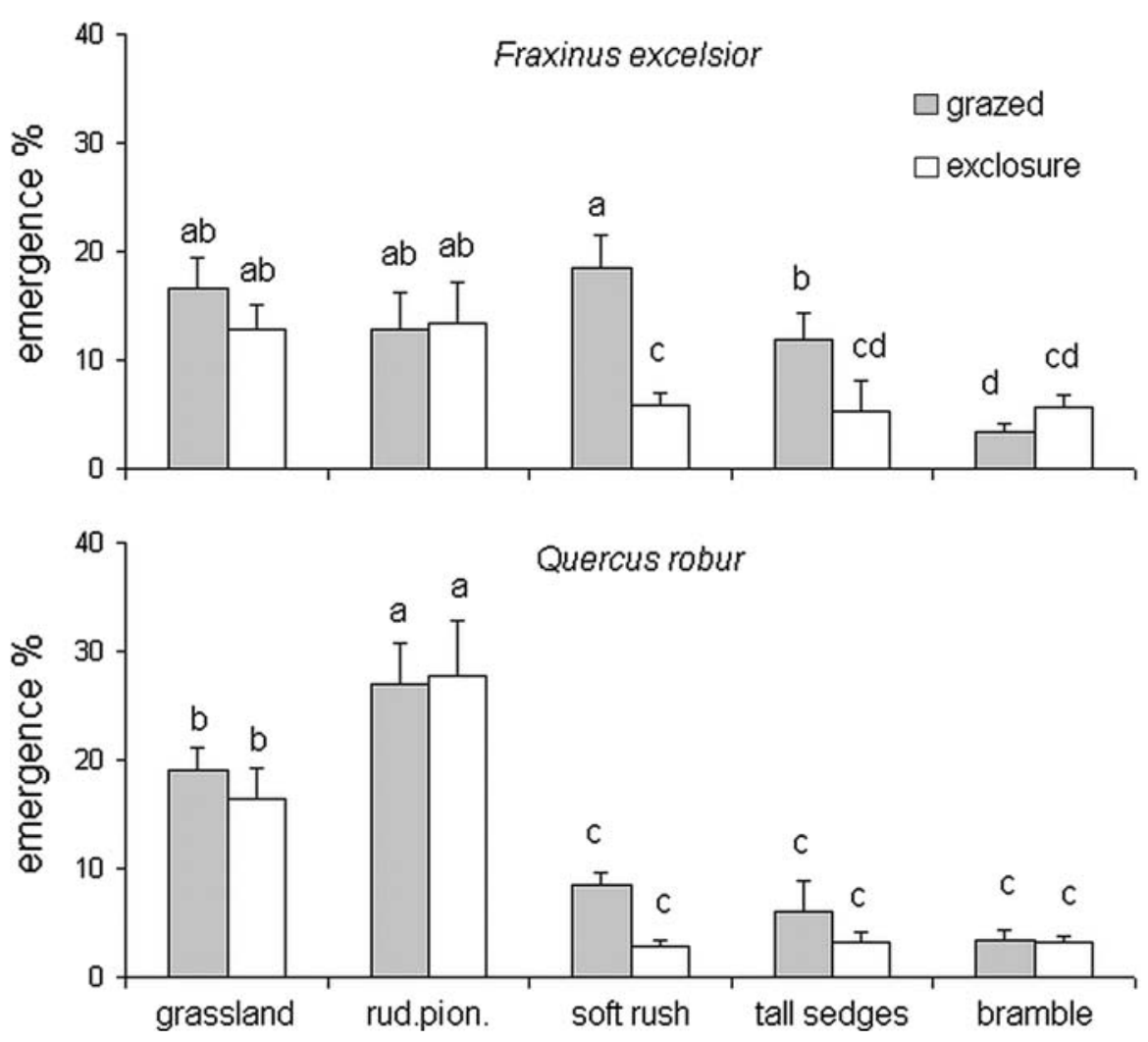

plots, cover was almost restored in May (Table 2), while in flooded plots recovery was delayed after trampling (cover in May $<72 \%$, with still visible hoof prints). Average canopy height of unclipped swards was comparable in flooded and unflooded plots, whether trampled or not, but variation in height was higher in flooded plots, reflecting the presence of gaps and taller grasses in the sward. In September, recovery and vegetation height (including variance) were similar in both flooded and dry plots, whether plots were trampled or not $(38.4 \pm 15.6 \mathrm{~cm})$. Light penetration was similar in all clipped plots $(>95 \%)$. In unclipped plots, mean light penetration ranged from 52.2 to $63.4 .3 \%$ in May, except for flooded and trampled plots: $87.1 \pm 9.4 \%$. In September, light penetration was comparable in all plots.

For both $Q$. robur and $F$. excelsior, the interaction of trampling and flooding increased emergence (Table 3, Fig. 2). Except for $Q$. robur in clipped plots, this effect was significant, but variation within flooding treatment was higher due to predation (see section "Methods"). Clipping enhanced the emergence of $Q$. robur, while it had a complex effect on $F$. excelsior: no effect in flooded plots and a significant but small negative effect in trampled, dry plots (significant clipping*trampling*flooding interaction). Other interactions did not show significant effects. Average emergence rate for $Q$. robur was $18.13 \%$ $( \pm 9.99)$; for $F$. excelsior it was $16.17 \%( \pm 10.24)$.

Shoot length of emerged seedlings after the first growing season was only significantly influenced by clipping the surrounding seed-bed vegetation (Table 4). In both species, mean shoot length in clipped grassland plots was higher $( \pm \mathrm{cm})$ than in tall grassland plots (Fig. 3).

\section{Discussion}

We found two patterns that apply for both $Q$. robur and F. excelsior: (1) emergence and early growth were favoured in short or sparse vegetation structure types and (2) emergence was positively affected by the interaction of pre-emergence flooding and trampling. Grazing interacted with vegetation structure and enhanced emergence of $F$. excelsior in tall Juncus and Carex vegetations. For $Q$. robur, clipping (simulated grazing) grassland swards enhanced 
Fig. 2 Emergence \% $(+\mathrm{SE})$ of tree seedlings (F. excelsior and $Q$. robur) under simulated grazing (clipped plots have a short grassland lawn vegetation; unclipped plots have a tall herb vegetation), simulated flooding (inundation during 3 weeks; dry plots were not inundated) and trampling. Numbers below $x$-axis of $Q$. robur represent numbers observations ( $n$ ) after acorn predation (for F. excelsior all $n=324$ ). Different letters indicate significantly different values (multiple comparisons with Tukeytests, $P<0.05)$ per species. Differences between species are not analysed
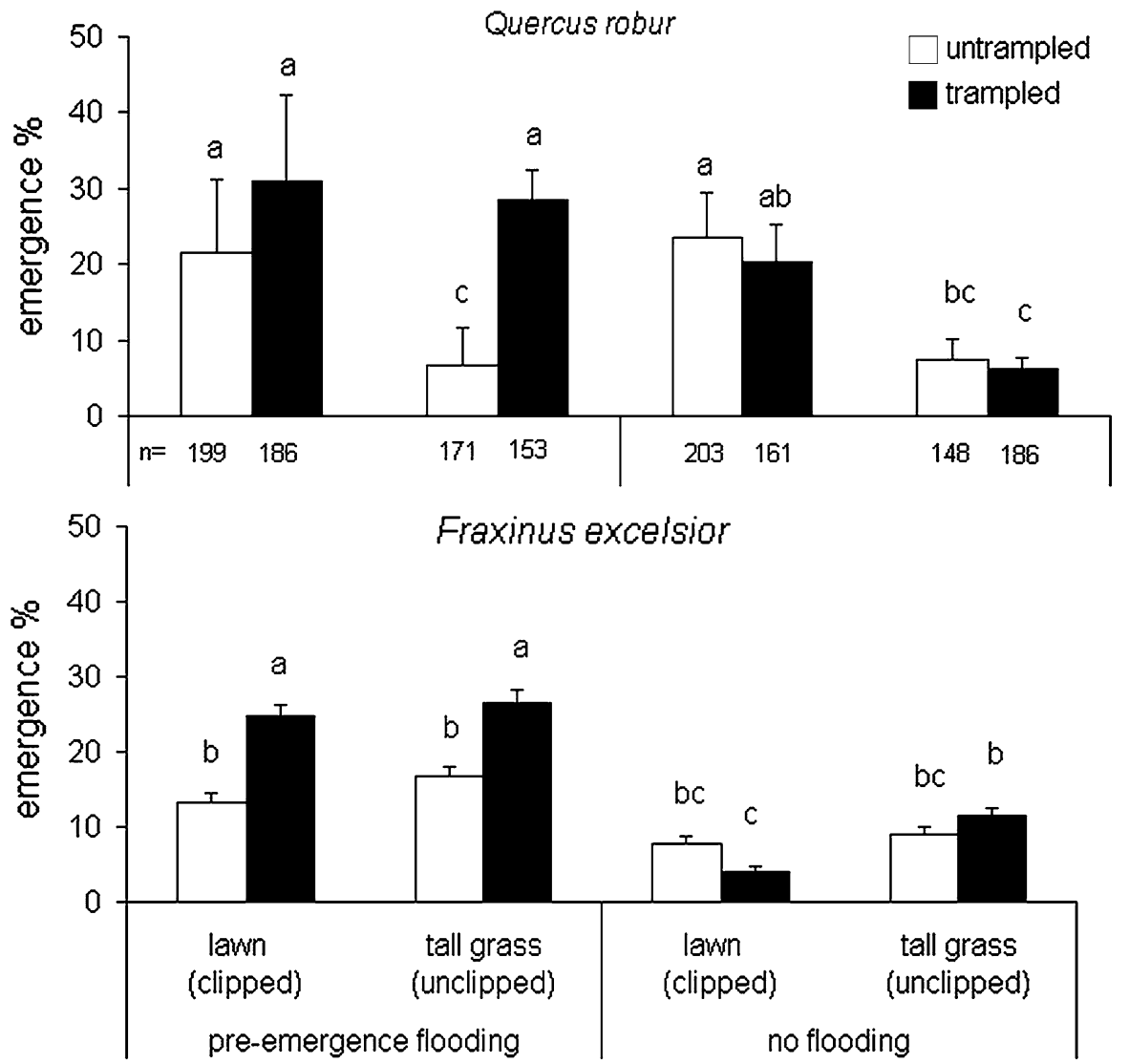

emergence. Our hypothesis that the effect of the large seed reserves of $Q$. robur would overrule the effects of disturbances and competition was rejected.

Vegetation structure and grazing interaction

In general, a closed grass canopy configuration is unfavourable for $F$. excelsior and $Q$. robur seedlings due to competition (Frost and Rydin 1997; Harmer and Robertson 2003). Although F. excelsior and $Q$. robur are relatively shade-tolerant species with regard to emergence (Jones 1959; Tapper 1992; Crawley and Long 1995), emergence was significantly higher in vegetation types with high light penetration (grassland, ruderal pioneer vegetation and grazed soft rush and tall sedges vegetation) than in vegetation types with low light penetration (ungrazed soft rush and tall sedges, bramble thickets).

The high emergence of $F$. excelsior seedlings in grazed, tall herb vegetation is probably related to the creation of gaps due to herbivore activity rather than reduced vegetation height. Gaps not only offer increased light penetration, but also better (buffered) soil humidity and temperature conditions for seedlings (Vandenberghe et al. 2006). Unpalatable vegetation types are not likely to be grazed but tall sedges are used as food supply in dry periods, and grazing (between) soft rush tussocks occurs occasionally (Van Uytvanck et al. 2008b). For $Q$. robur seedlings, grazing of tall herb vegetation did not result in a comparable (significant) increase in emergence. In contrast, simulation of grazing grassland swards clearly enhanced the emergence of $Q$. robur, but vegetation height of the clipped grass lawns was much lower than the grazed vegetation types in the field experiment. Seedling light requirements of $Q$. robur are higher than for $F$. excelsior (Ziegenhagen and Kausch 1995), which might explain the lack of a significant effect of clipping on emergence of $F$. excelsior seedlings. 
Table 4 Shoot heightresults of the GLM analyses

Independent factors:

clipping (the surrounding seed-bed vegetation), trampling and flooding

\begin{tabular}{llllrr}
\hline & Independent factor & Nom. df & Den. df & $F$ value & Pr $>F$ \\
\hline F. excelsior & Clipping seed-bed vegetation & 1 & 359 & 39.83 & 0.002 \\
& Flooding & 1 & 359 & 2.33 & 0.162 \\
& Trampling & 1 & 359 & 1.13 & 0.403 \\
& Clipping*trampling & 1 & 359 & 0.46 & 0.500 \\
& Clipping*flooding & 1 & 359 & 0.11 & 0.742 \\
& Trampling*flooding & 1 & 359 & 0.01 & 0.932 \\
& Clipping*trampling*flooding & 1 & 359 & 3.01 & 0.198 \\
& Clipping seed-bed vegetation & 1 & 243 & 37.24 & $<0.001$ \\
& Flooding & 1 & 243 & 2.16 & 0.248 \\
& Trampling & 1 & 243 & 0.98 & 0.424 \\
& Clipping*trampling & 1 & 243 & 1.66 & 0.374 \\
& Clipping*flooding & 1 & 243 & 3.05 & 0.156 \\
& Trampling*flooding & 1 & 243 & 0.05 & 0.830 \\
& Clipping*trampling*flooding & 1 & 243 & 0.22 & 0.642 \\
\hline
\end{tabular}

Fig. 3 Shoot length $(+\mathrm{SE})$, after the first growing season, of emerged tree seedlings ( $F$. excelsior and $Q$. robur) under simulated grazing (clipped plots have short grassland lawn vegetation; unclipped plots have tall herb vegetation), simulated flooding (inundation during 3 weeks; dry plots were not inundated) and trampling. Numbers below $x$-axis of $Q$. robur represent numbers observations ( $n$ ) after acorn predation (for $F$. excelsior all $n=324)$. Different letters indicate significantly different values (multiple comparisons with Tukeytests, $P<0.05)$ per species. Differences between species are not analysed
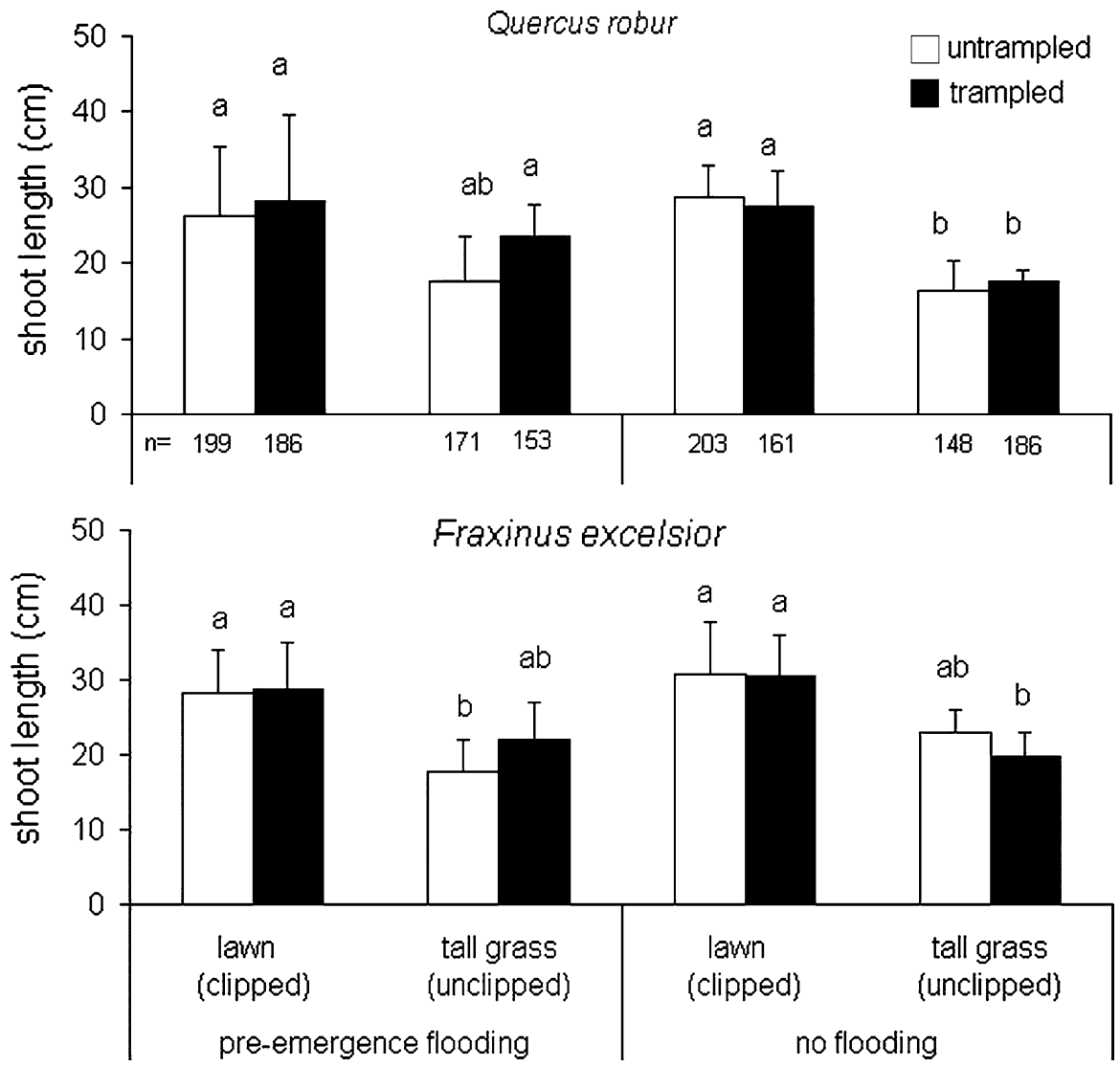

Flooding and herbivore disturbances

Moist conditions in disturbed soils are often a critical constraint for tree germination. Too wet conditions as a result of standing water in (hoof print) gaps may prevent or retard establishment (Nilsson et al. 2002). In particular on heavy soils (loam, clay), standing water in gaps may occur, but it was not the case in our 
simulation experiment. For both $Q$. robur and $F$. excelsior, the combination of trampling and flooding resulted in higher emergence. This combination seems to affect the structure of the grass sward more drastically than trampling dry swards: severe damage to grass roots and above ground grass vegetation most probably reduced above- and below-ground competition and retarded sward recovery. Van Uytvanck et al. (2008a) found that the regeneration pattern of $F$. excelsior on grazed floodplains was enhanced in tall herb vegetation patches (compared to short grassland) on temporarily flooded soils. Subsequently, emerged seedlings in hoof print gaps were temporarily protected from grazing by unpalatable tall herbs via associational resistance (cf. Callaway et al. 2000; Smit et al. 2005). Gaps and vegetation removal are known to improve tree seedling emergence (Agestam et al. 2003; Vandenberghe et al. 2006). Gap creation by soil trampling may also reduce seed predation (mainly by insects) compared to dense vegetations (Nystrand and Granstrom 2000; Smit et al. 2006). In a later life stage however, trampling of seedlings by large herbivores may be a main agent for mortality (e.g. in grazed mountain shrubland, Gómez et al. 2003).

Overgrowth of seedlings by neighbouring vegetation implies reduced light, space and nutrient availability (Vandenberghe et al. 2008). In our experiment, seedlings had the highest shoot growth in clipped plots, while there was no effect of trampling. Trampling had only temporary effects: increased variation in sward height, reduction of sward cover and increased light penetration were found in May, but no more in September. Therefore, we suppose that trampling rather affects emergence than subsequent growth. Clipping increased light penetration during the whole growing season. Establishing seedlings tend to compete size-symmetrically with grass competitors early in development, but interactions between root and shoot competition could occur as woody seedlings become more dominant in the vegetation size hierarchy (Bloor et al. 2008). Clipping surrounding grass vegetation affects this competition and probably induces a size-asymmetric above-ground competition for light (Weiner 1990). Our results suggest that emerging seedlings in clipped plots had a continuous advantage to grow under reduced light competition. Below-ground competition was probably low due to the nutrient rich seed-bed plots and permanent water supply in our experiment. Under such reduced stress conditions, enhanced shoot or stem growth is to be expected (Davis et al. 1999; Husheer et al. 2006). However, the positive effect of a low surrounding grassland vegetation in our experiment may not be equally present in permanently grazed, natural conditions due to associated palatability (i.e. seedlings are eaten together with surrounding palatable grassland vegetation, Olff et al. 1999).

\section{Seed-seedling conflicts in the recruitment process}

In the light of definitive tree establishment, our results suggest that in grazed ecosystems, there is a discordant relationship between seedling emergence and seedling survival and growth in the process of tree recruitment. First, seed-seedling conflicts can occur in seed dispersal across a mosaic landscape, in which a trade-off mechanism optimises between predation avoidance (cf. F. excelsior with winged fruits) and nutritional support of the establishing seedling (cf. $Q$. robur with large and heavy seeds). Second, and similar to protective capacities of vegetation patches against grazing, environmental conditions (moist, light, nutrients) may favour the survival and growth of a seedling in some patches more than in others. Seed-seedling conflicts can occur during both of these phases of recruitment if (micro)sites or conditions that are suitable for seeds are unsuitable for seedlings (Schupp 1995). In grazed ecosystems, growth and survival of seedlings are highly restricted in vegetation types that favour emergence due to reduced competition (grassland, pioneer and tall herb vegetation). In contrast, unpalatable tall herb vegetation and scrub favour survival and growth due to associational resistance (Van Uytvanck et al. 2008b), but suppress emergence due to strong competition. Counteractive effects of grazing on different stages increase the complexity of the recruitment process and the uncertainty about the amount of individuals reaching the adult stage (Pérez-Camacho and Rebollo 2009). The complexity of tree regeneration in grazed ecosystems such as wood pastures was further elaborated by Smit et al. (2006), who found that removal of seeds was higher inside safe sites for seedlings than outside. Aggregated predation by different granivorous animals (insects, rodents, birds, cattle) was of great importance under nurse structures that did not prevent but rather enhance seed predation. Therefore, safe 
sites that protect seedlings from grazing by definition are not necessarily safe sites for seeds.

\section{Conclusions}

Interaction between large herbivore activities and flooding positively affects emergence of tree seedlings with variable recruitment strategies. However, the above-mentioned conflicts represent just as much bottlenecks in the definitive establishment of woody species. They can have a major impact on the overall quantity of recruitment at the landscape level and on the distribution of recruitment among patches. Our data suggest that tree recruitment of palatable species in open landscape types, such as grazed floodplains, may start via microsite creation caused by large herbivore grazing and/or trampling. For subsequent growth and survival however, protective structures such as tall herb or scrub patches are needed. This implicates the need of a dynamic vegetation structure, offering changing patch qualities in space and time for tree species with different recruitment strategies (in our case $Q$. robur and $F$. excelsior). Large herbivores are able to regulate the balance between woody and herbaceous vegetation and maintain or develop finemeshed (often mid-successional) mosaic landscapes including grassland, scrub, scattered trees and woodland patches (Bokdam and Gleichman 2000; Vera 2000; Hodder et al. 2005). The dynamic functioning of these landscapes may be explained by the shifting mosaics model of Olff et al. (1999) that is driven by large herbivores. We conclude that recruitment of native tree species assemblages may not only require an appropriate grazing regime, but also the restoration of natural disturbances, such as natural floods in floodplain areas.

Acknowledgements We thank the Flanders Marine Institute (VLIZ) to put the greenhouse and garden facilities at our disposal, the NGO Natuurpunt to grant us permission to set up the field experiment in three nature reserves, the BMK-team of the Research Institute for Nature and Forest for statistical support, Dirk Maes and two anonymous reviewers for their for useful comments on the manuscript.

\section{References}

Agestam E, Eko PM, Nilsson U, Welander NT (2003) The effects of shelterwood density and site preparation on natural regeneration of Fagus sylvatica in southern Sweden. For Ecol Manage 176:61-73

Berkowitz AR, Canham CD, Kelly VR (1995) Competition vs facilitation of tree seedling growth and survival in early successional communities. Ecology 76:1156-1168

Bloor JMG, Leadley PW, Barthes L (2008) Responses of Fraxinus excelsior seedlings to grass-induced above- and below-ground competition. Plant Ecol 194:293-304

Bokdam J, Gleichman JM (2000) Effects of grazing by freeranging cattle on vegetation dynamics in a continental north-west European heathland. J Appl Ecol 37:415-431

Caccia FD, Ballaré CL (1998) Effects of tree cover, understory vegetation, and litter on regeneration of Douglas-fir (Pseudotsuga menziesii) in southwestern Argentina. Can J Forest Res 28:683-692

Callaway RM, Kikvidze Z, Kikodze D (2000) Facilitation by unpalatable weeds may conserve plant diversity in overgrazed meadows in the Caucasus Mountains. Oikos 89: 275-282

Clarke PJ (2002) Experiments on tree and shrub establishment in temperate grassy woodlands: seedling survival. Aust Ecol 27:606-615

Crawley MJ, Long CR (1995) Alternate bearing, predator satiation and seedling recruitment in Quercus robur $\mathrm{L}$. J Ecol 83:683-696

Davis MA, Wrage KJ, Reich PB, Tjoelker MG, Schaeffer T, Muermann C (1999) Survival, growth, and photosynthesis of tree seedlings competing with herbaceous vegetation along a water-light-nitrogen gradient. Plant Ecol 145: 341-350

Deiller AF, Walter JMN, Tremolieres M (2003) Regeneration strategies in a temperate hardwood floodplain forest of the Upper Rhine: sexual versus vegetative reproduction of woody species. For Ecol Manage 180:215-225

Eriksson O, Ehrlén J (1992) Seed and microsite limitation of recruitment in plant populations. Oecologia 91:360-364

Frost I, Rydin H (1997) Effects of competition, grazing and cotyledon nutrient supply on growth of Quercus robur seedlings. Oikos 79:53-58

Gardner G (1977) The reproductive capacity of Fraxinus excelsior on the Derbyshire Limestone. J Ecol 65: 107-118

Gómez JM, Garcia D, Zamora R (2003) Impact of vertebrate acorn- and seedling-predators on a Mediterranean Quercus pyrenaica forest. For Ecol Manage 180:125-134

Greiling DA, Kichanan N (2002) Old-field seedling responses to insecticide, seed addition, and competition. Plant Ecol 159:175-183

Grubb PJ (1988) The uncoupling of disturbance and recruitment, 2 kinds of seed bank, and persistence of plantpopulations at the regional and local scales. Ann Zool Fenn 25:23-36

Hagenah N, Munkert H, Gerhardt K, Olff H (2009) Interacting effects of grass height and herbivores on the establishment of an encroaching savanna shrub. Plant Ecol 201:553-566

Harmer R, Robertson M (2003) Seedling root growth of six broadleaved tree species grown in competition with grass under irrigated nursery conditions. Ann For Sci 60:601-608

Hodder KH, Bullock JM, Buckland BC, Kirby KJ (2005) Large herbivores in the wildwood and in modern naturalistic grazing systems. English Nature, Peterborough 
Husheer SW, Robertson AW, Coomes DA, Frampton CM (2006) Herbivory and plant competition reduce mountain beech seedling growth and establishment in New Zealand. Plant Ecol 183:245-256

Jones EW (1959) Biological flora of the British Isles: Quercus L. J Ecol 47:169-222

Jurena PN, Archer S (2003) Woody plant establishment and spatial heterogeneity in grasslands. Ecology 84:907-919

Kelt DA, Meserve PL, Forister ML, Nabors LK, Gutierrez JR (2004) Seed predation by birds and small mammals in semiarid Chile. Oikos 104:133-141

Kühne C, Bartsch N (2007) Germination of acorns and development of oak seedlings following flooding (Quercus robur L.) following flooding. J For Sci 53:391-399

Mazia CN, Chaneton EJ, Ghersa CM, Leon RJC (2001) Limits to tree species invasion in Pampean grassland and forest plant communities. Oecologia 128:594-602

Nilsson U, Gemmel P, Johansson U, Karlsson M, Welander T (2002) Natural regeneration of Norway spruce, Scots pine and birch under Norway spruce shelterwoods of varying densities on a mesic-dry site in southern Sweden. For Ecol Manage 161:133-145

Nystrand O, Granstrom A (2000) Predation on Pinus sylvestris seeds and juvenile seedlings in Swedish boreal forest in relation to stand disturbance by logging. J Appl Ecol 37:449-463

Oberdorfer E (1992) Süddeutsche Pflanzengesellschaften: Teil 4: Wälder und Gebüsche. Fischer, Jena, Germany

Olff H, Vera FWM, Bokdam J, Bakker ES, Gleichman JM, De Maeyer K, Smit R (1999) Shifting mosaics in grazed woodlands driven by the alternation of plant facilitation and competition. Plant Biol 1:127-137

Pérez-Camacho L, Rebollo S (2009) Are irrigation and grazing effects transferred, accumulated or counteracted during plant recruitment? Plant Ecol 201:501-515

Posada JM, Mitchell Aide T, Cavelier J (2000) Cattle and weedy shrubs as restoration tools of tropical montane rainforest. Restor Ecol 8:370-379

Putman RJ (1986) Grazing in temperate ecosystems. Large herbivores and the ecology of the New Forest. Croom Helm, Beckenham

Rackham O (1980) Ancient woodland. Its history, vegetation and uses in England. London, UK

Raquin C, Jung-Muller B, Dufour J, Frascaria-Lacoste N (2002) Rapid seedling obtaining from European ash species Fraxinus excelsior (L.) and Fraxinus angustifolia (Vahl.). Ann For Sci 59:219-224

Reyes O, Casal M (2006) Seed germination of Quercus robur, $Q$. pyrenaica and $Q$. ilex and the effects of smoke, heat, ash and charcoal. Ann For Sci 63:205-212

Rudinger MCD, Dounavi A (2008) Underwater germination potential of common ash seed (Fraxinus excelsior L.) originating from flooded and non-flooded sites. Plant Biol 10:382-387

Schupp EW (1995) Seed seedling conflicts, habitat choice, and patterns of plant recruitment. Am J Bot 82:399-409
Setterfield SA (2002) Seedling establishment in an Australian tropical savanna: effects of seed supply, soil disturbance and fire. J Appl Ecol 39:949-959

Smit C, Beguin D, Buttler A, Muller-Scharer H (2005) Safe sites for tree regeneration in wooded pastures: a case of associational resistance? J Veg Sci 16:209-214

Smit C, Gusberti M, Muller-Scharer H (2006) Safe for saplings; safe for seeds? For Ecol Manage 237:471-477

Tapper PG (1992) Demography of persistent juveniles in Fraxinus excelsior. Ecography 15:385-392

Tapper PG (1996) Tree dynamics in a successional AlnusFraxinus woodland. Ecography 19:237-244

Thompson K, Bekker RM (1997) Soil seed banks of NW Europe: methodology. density and longevity. Cambridge University Press, Cambridge

Trimble SW, Mendel AC (1995) The cow as a geomorphic agent-a critical review. Geomorphology 13:233-253

van der Valk AG, Warner BG (2009) The development of patterned mosaic landscapes. Plant Ecol 200:1-7

Van Splunder I, Coops H, Voesenek LAC, Blom CWP (1995) Establishment of alluvial forest species in floodplains: the role of dispersal timing, germination characteristics and water level fluctuations. Acta Bot Neerl 44:269-278

Van Uytvanck J, Decleer K, Hoffmann M (2008a) Establishment patterns of woody species in low intensity grazed pastures after the cessation of intensive agricultural use. For Ecol Manage 256:106-113

Van Uytvanck J, Maes D, Vandenhaute D, Hoffmann M (2008b) Restoration of woodpasture on former agricultural land: the importance of safe sites and time gaps before grazing for tree seedlings. Biol Conserv 141:78-88

Vandenberghe C, Frelechoux F, Gadallah F, Buttler A (2006) Competitive effects of herbaceous vegetation on tree seedling emergence, growth and survival: does gap size matter? J Veg Sci 17:481-488

Vandenberghe C, Frelechoux F, Buttler A (2008) The influence of competition from herbaceous vegetation and shade on simulated browsing tolerance of coniferous and deciduous saplings. Oikos 117:415-423

Vera FWM (2000) Grazing ecology and forest history. CABI Publishing, Oxon, UK

Wardle P (1961) Biological flore of the British Isles: Fraxinus excelsior L. J Ecol 49:739-751

Weiner J (1990) Asymmetric competition in plant-populations. Trends Ecol Evol 5:360-364

Willoughby I, Jinks RL, Kerr G, Gosling PG (2004) Factors affecting the success of direct seeding for lowland afforestation in the UK. Forestry 77:467-482

Winn AA (1985) Effects of seed size and microsite on seedling emergence of prunella vulgaris in four habitats. J Ecol 73: $831-840$

Ziegenhagen B, Kausch W (1995) Productivity of young shaded oaks (Quercus robur L.) as corresponding to shoot morphology and leaf anatomy. For Ecol Manage 72: 97-108 